\title{
Theoretical investigation on crystal structure, detonation performance and thermal stability of a high density cage hexanitrohexaazaisowurtzitane derivative
}

\author{
LI XIAO-HONG ${ }^{\mathrm{a}, \mathrm{b}, *}$, CUI HONG-LING ${ }^{\mathrm{a}, \mathrm{b}}$, LI LI-BEN ${ }^{\mathrm{a}, \mathrm{b}}$ and ZHANG XIAN-ZHOU ${ }^{\mathrm{c}}$ \\ ${ }^{a}$ College of Physics and Engineering, ${ }^{b}$ Luoyang Key Laboratory of Photoelectric Functional Materials, \\ Henan University of Science and Technology, Luoyang 471003, China \\ ${ }^{\mathrm{c} C o l l e g e ~ o f ~ P h y s i c s ~ a n d ~ I n f o r m a t i o n ~ E n g i n e e r i n g, ~ H e n a n ~ N o r m a l ~ U n i v e r s i t y, ~ X i n x i a n g, ~ 453007, ~ C h i n a ~}$ \\ e-mail: lorna639@126.com
}

MS received 18 December 2012; revised 15 February 2013; accepted 1 March 2013

\begin{abstract}
Density functional theory calculations were performed to study the new polynitro cage compound with the similar framework of HNIW. IR spectrum, heat of formation and thermodynamic properties were predicted. The bond dissociation energies and bond orders for the weakest bonds were analysed to investigate the thermal stability of the title compound. The detonation and pressure were evaluated by using the KamletJacobs equations based on the theoretical density and condensed HOFs. In addition, the results show that there exists an essentially linear relationship between the WBIs of $\mathrm{N}_{-} \mathrm{NO}_{2}$ bonds and the charges $-\mathrm{Q}_{\mathrm{NO} 2}$ on the nitro groups. The crystal structure obtained by molecular mechanics belongs to $\mathrm{P} 2_{1} / \mathrm{C}$ space group, with lattice parameters $\mathrm{Z}=4, \mathrm{a}=12.3421 \AA, \mathrm{b}=24.6849 \AA, \mathrm{c}=20.4912 \AA, \rho=1.896 \mathrm{~g} \mathrm{~cm}^{-3}$. The designed compound has high thermal stability and good detonation properties and is a promising high energy density compound.
\end{abstract}

Keywords. Density functional theory; heat of formation; detonation properties; bond dissociation energy; thermodynamic properties.

\section{Introduction}

Energetic nitrogen-rich compounds have many potential applications in high explosives and rocket propellant formulations. And they have received considerable attention because of their superior explosive performance over the currently used materials. ${ }^{1}$ Among various types of high energy density materials (HEDMs), high-nitrogen compounds constitute a unique class of energetic materials and have received a substantial amount of interests because they possess favourable insensitivity, explosive performance and higher heats of formation (HOF) due to higher percentages of decomposition product and the presence of inherently energetic $\mathrm{N}-\mathrm{N}$ and $\mathrm{C}-\mathrm{N}$ bonds. ${ }^{1-5}$

Highly nitrated cage molecules such as hexanitrohexaazaisowurtzitane (HNIW, CL-20), ${ }^{6}$ polynitroadamantanes (PNAs), ${ }^{7,8}$ octanitrocubane (ONC), ${ }^{9-11}$ and 4-trinitroethyl-2,6,8,10,12-pentanitrohexaazaisowurtzitane (TNE-HNIW) ${ }^{12,13}$ have therefore gained much attention in recent years. The cage compounds derive most of energy from their heat of formation. In addition, they have compact structures and can release

*For correspondence additional energy upon detonation because of the cage strain in these systems. The classical explosives derive their energy from oxidation of carbon backbone. The difference between the cage compounds and classic explosives makes the cage compounds to gain much attention. ${ }^{12,13}$

Properties are often manipulated by making structural modifications, so it is necessary and important to predict the properties and performance of the new candidates of HEDM before the laborious and expensive synthesis. Therefore, the primary step for searching and synthesizing HEDMs is to optimize the designed HEDMs with high density and energy.

To find new candidates of HEDM, it is necessary and important to predict the properties and performance of the proposed structures before the laborious and expensive synthesis. For example, experiment showed that TNE-HNIW is a potential explosive and has higher stability than HNIW, ${ }^{12}$ while the theoretical calculation not only support the experimental result, but also show that it has better detonation properties than HNIW. ${ }^{13}$ Because of comprehensive advantages of highly nitrated cage molecules, a new HNIW derivative has been designed (figure 1). Its structural and energetic properties, such as thermodynamic properties, 


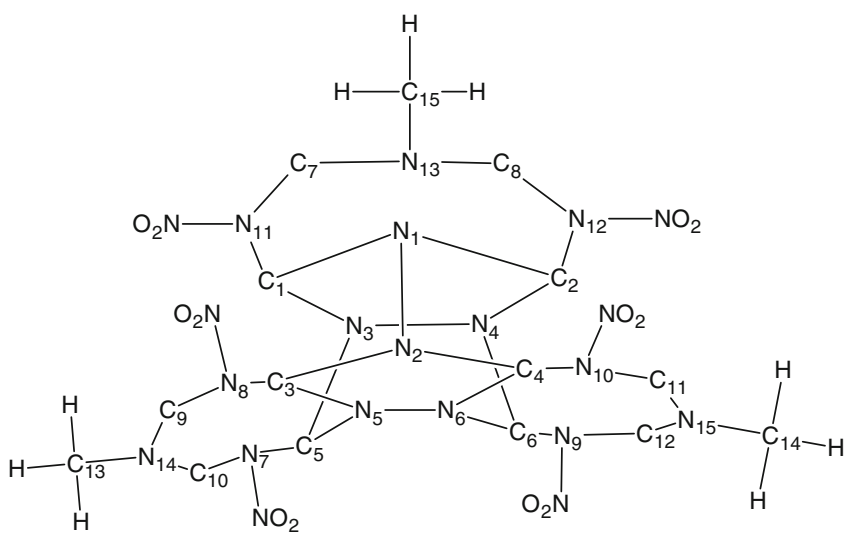

Figure 1. Molecular structure of the title compound.

crystal density, detonation performance and thermal stability have been studied using density functional theory (DFT). Through the theoretical study, it is possible to screen for approximate compounds avoiding hazardous and experimental studies.

\section{Computational methods and details}

The DFT-B3LYP method is widely used in many investigations ${ }^{14-16}$ because it could give reasonable energies, molecular structures, and infrared vibrational frequencies. In this paper, the title compound is fully optimized to obtain its molecular geometry and electronic structure at spin-unrestricted method B3LYP/6-31G**. Vibrational analysis is performed thereafter at the same level with the Gaussian03 program package. ${ }^{17}$ Since the DFT-calculated harmonic vibrational frequencies are usually larger than those observed experimentally, they are scaled by using a factor of 0.96 as was done before. ${ }^{18}$

The NBO calculations were performed using the NBO 3.1 program as implemented in the Gaussian 03 package ${ }^{17}$ at B3LYP/6-31G** level. Detonation velocity $(D)$ and pressure $(P)$ are the most important targets of scaling the detonation characteristics of energetic materials. For the explosives with $\mathrm{CHNO}$ elements, these parameters can be calculated using the KamletJacbos (K-J) equations: ${ }^{19,20}$

$$
\begin{gathered}
D=0.7062 \times \Phi^{0.5}(1.0+1.3 \rho) \\
\Phi=N \bar{M}^{0.5} Q^{0.5} \\
P=7.617 \times 10^{8} \Phi \rho^{2},
\end{gathered}
$$

where each term in Eqs. (1) and (2) is defined as follows: $P$, detonation pressure $(\mathrm{GPa})$; $D$, the detonation velocity $(\mathrm{km} / \mathrm{s}) ; \rho$, the packed density $\left(\mathrm{g} / \mathrm{cm}^{3}\right) ; \Phi$, the characteristics value of explosives; $N$, the mol of gas produced by per gram of explosives; $\bar{M}$, an average molar weight of detonation products; and $Q$, the estimated heat of detonation $(\mathrm{kJ} / \mathrm{g})$.

The density of each compound was predicted from the molecular volume divided by molecular weight, and the molecular volume of each molecule was yielded from the statistical average of 100 single-point molar volume calculations for each optimized structure. The molar volume was defined as inside a contour of 0.001 electrons $/ \mathrm{Bohr}^{3}$ density that was evaluated using a Monte-Carlo integration implemented in the Gaussian $03^{17}$ program. This method has accurately predicted the densities, detonation velocities, and detonation pressures of the explosives. ${ }^{21-25}$ Recently, an efficient and convenient way has been worked out to predict the crystalline densities of energetic materials containing $\mathrm{C}, \mathrm{H}, \mathrm{N}$ and $\mathrm{O}$ elements. Studies ${ }^{26}$ have indicated that the theoretical molecular density is very close to the experimental crystal density when the average molar volume $\mathrm{V}$ estimated by Monte-Carlo method based on 0.001 electrons $/$ bohr $^{3}$ density space at the $\mathrm{B} 3 \mathrm{LYP} / 6-31 \mathrm{G}^{* *}$ or $6-31 \mathrm{G}^{*}$ level is used.

The possible polymorphs and crystal structure of the title compound is predicted by rigorous molecular packing calculations using polymorph module of Material Studio ${ }^{27}$ since high-energy compounds are usually in condensed phases, especially solid form. The compass force-field is used to search the possible molecular packing among the most probable seven space groups $\left(\left(\mathrm{P} 2_{1} / \mathrm{c}, \mathrm{P}-1, \mathrm{P} 2_{1} 2_{1} 2_{1}, \mathrm{Pbca}, \mathrm{C} 2 / \mathrm{c}, \mathrm{P} 2_{1}\right.\right.$, and $\left.\mathrm{Pna} 2{ }_{1}\right){ }^{28-32}$

Bond dissociation energy (BDE) is used to evaluate the pyrolysis mechanism and thermal stability. BDE is defined as the difference between the energies of the parent molecule and the corresponding radicals in the unimolecular bond dissociation. ${ }^{33,34}$

The gas-phase BDE for a bond $\mathrm{R}_{1}-\mathrm{R}_{2}$ is defined as the enthalpy change of the bond homolysis reaction at $298 \mathrm{~K}$ in a vacuum, which can be calculated from the sum of enthalpies of the products (radicals) minus that of reactant (parent molecule).

$$
\begin{aligned}
R_{1}-R_{2}(g) \rightarrow & R_{1} \cdot(g)+R_{2} \cdot(g) \\
\operatorname{BDE}\left(R_{1}-R_{2}\right)= & H_{298}\left(R_{1 .} \cdot\right)+H_{298}\left(R_{2 .} \cdot\right) \\
& -H_{298}\left(R_{1 .}-R_{2}\right),
\end{aligned}
$$

where $R_{1}-R_{2}$ denotes the neutral molecules, $R_{1}$. and $R_{2}$. stand for the corresponding product radicals after the bond dissociation; $\operatorname{BDE}\left(R_{1}-R_{2}\right)$ is the bond dissociation enthalpy of the bond $R_{1}-R_{2}$. The latter three items in Eq. (4) are the enthalpies of the corresponding radicals and the parent compound, respectively. Here, 
the calculations of geometry and energy for all radicals were also performed using the spin-unrestricted method B3LYP/6-31G**.

\section{Results and discussion}

\subsection{Infrared spectrum}

The IR spectrum is one basic property of a compound. It is often used to analyse or identify substances and has a direct relation with the thermodynamic properties. Therefore, it is of great significance to calculate the IR and thermodynamic properties of the title compound by a theoretical method. Here, vibrational frequencies were calculated by using DFT B3LYP/6-31G** level. Figure 2 presents the simulated IR spectrum based on the scaled harmonic vibrational frequencies.

Obviously, there are six main characteristic regions. The modes in $2691-3290 \mathrm{~cm}^{-1}$ are associated with C$\mathrm{H}$ stretch. In this region, the strongest characteristic peak is at $2860 \mathrm{~cm}^{-1}$. The modes in $1661-1708 \mathrm{~cm}^{-1}$ are associated with the $\mathrm{N}=\mathrm{O}$ asymmetric stretch of nitro groups and the strong characteristic peak is at $1621 \mathrm{~cm}^{-1}$. The remarkable signal at $1278 \mathrm{~cm}^{-1}$ is characterized to the $\mathrm{N}=\mathrm{N}$ stretch.
Band at $1204 \mathrm{~cm}^{-1}$ is composed of the $\mathrm{C}-\mathrm{N}$ stretch, the $\mathrm{C}-\mathrm{H}$ wagging. Band at $1029 \mathrm{~cm}^{-1}$ is composed of the $\mathrm{C}-\mathrm{N}$ stretch, the $\mathrm{C}-\mathrm{H}$ wagging together with the $\mathrm{N}-\mathrm{N}$ stretch. The weak peaks less than $900 \mathrm{~cm}^{-1}$ are mainly caused by the deformation of the heterocycle skeleton and the bending vibration of $\mathrm{C}-\mathrm{H}$ bond.

\subsection{Heat of formation}

Heat of formation (HOF) is taken to be indicative of the 'energy content' of a HEDM, which can be used to estimate the amount of energy released or absorbed in a chemical reaction. In addition, HOF can also calculate other thermodynamic functions. Atomization reaction or isodesmic reaction method can be used to obtain the standard heats of formation (HOF) at $298.15 \mathrm{~K}$. In this paper isodesmic reaction method is employed. Isodesmic reaction, where the numbers of bonds and bond types are preserved on both sides of the reaction, often leads to cancellation of systematic errors resulting from the bond environments, spin contamination, basis set superposition and other nonrandom factors. ${ }^{35}$ The accuracy of HOF obtained theoretically is conditioned by the reliability of HOF of the reference compounds.

The HOF for the title compound can be derived from the following isodesmic reaction.
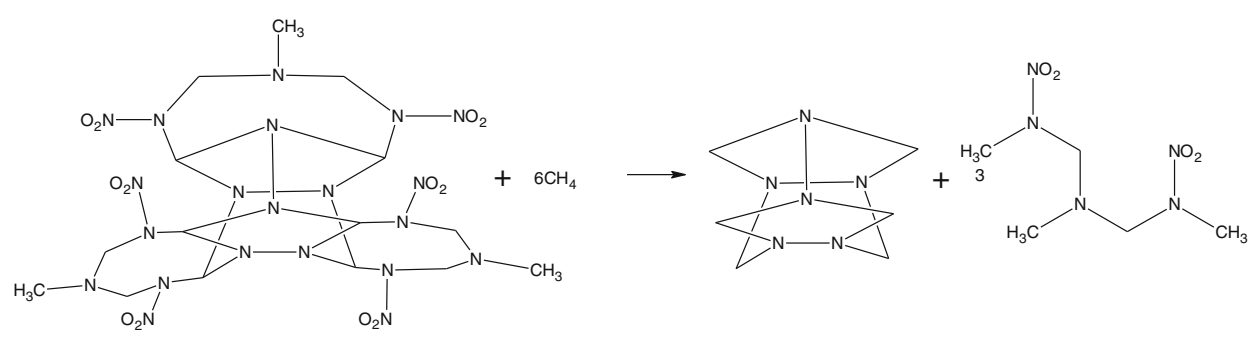

While the heats of formation for the products can be obtained by the following isodesmic reaction:
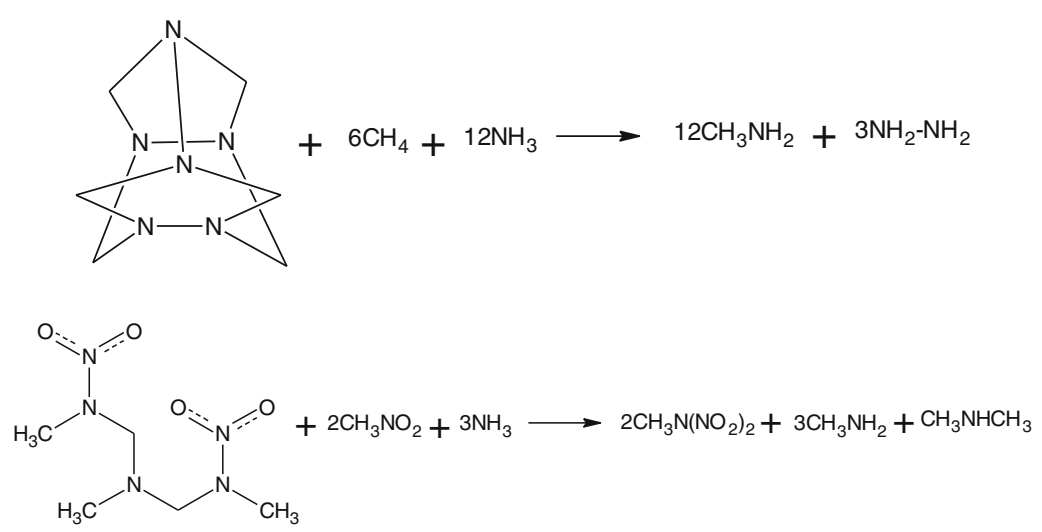


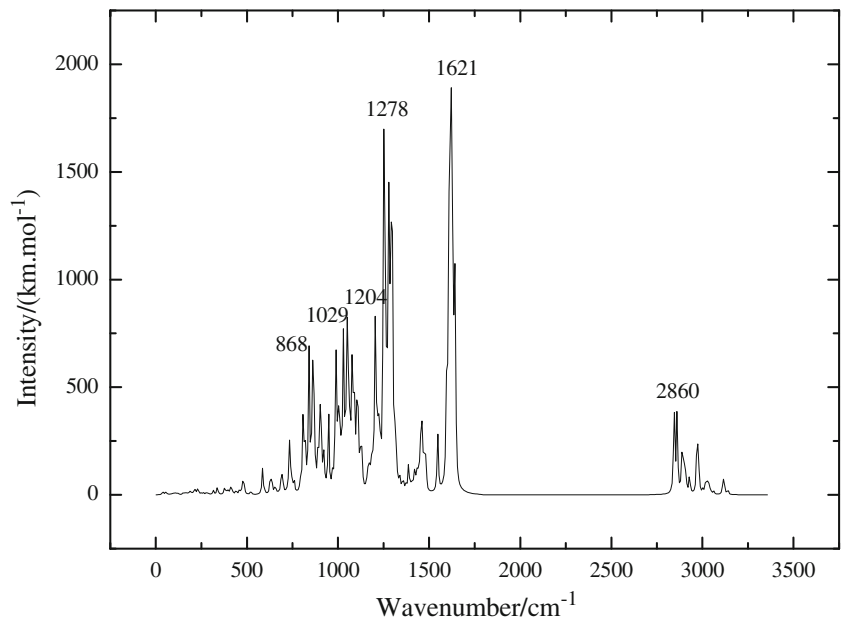

Figure 2. The simulated infrared spectrum for the title compound.

Table 1 collects the total energies $\left(\mathrm{E}_{0}\right)$ and HOFs of the species involved in the reaction. The experimental HOF of HNIW is also listed in table 1.

The HOF of the designed cage compound is $1643.265 \mathrm{~kJ} / \mathrm{mol}$, which is much bigger than that of HNIW and benefit the heat release during the detonation.

\subsection{Detonation properties}

Detonation velocity $(D)$ and pressure $(P)$ are the important parameters to evaluate the performances of energetic materials. As for $\mathrm{C}, \mathrm{H}, \mathrm{O}$, and $\mathrm{N}$-containing explosives, they can be estimated using the KamletJacobs equation. ${ }^{39,40}$ Further, we computed the condensed phase heat of formation of the title compound through the method of Byrd and Rice. ${ }^{41}$ The $\mathrm{OB}_{100}$ are calculated using the formula (8), which can be

Table 1. Calculated energies and HOF of species involved in the reaction.

\begin{tabular}{lcc}
\hline Compound & $\mathrm{E}_{0}(\mathrm{a} . \mathrm{u})$ & $\mathrm{HOF}(\mathrm{kJ} / \mathrm{mol})$ \\
\hline $\mathrm{CH}_{4}$ & -40.473159 & $-74.4^{\mathrm{a}}$ \\
$\mathrm{CH}_{3} \mathrm{NO}_{2}$ & -245.042003 & $-80.8^{\mathrm{a}}$ \\
$\mathrm{NH}_{3}$ & -56.548470 & $-45.9^{\mathrm{a}}$ \\
$\mathrm{CH}_{3} \mathrm{~N}_{\left(\mathrm{NO}_{2}\right)_{2}}$ & -504.889403 & $43.1^{\mathrm{b}}$ \\
$\mathrm{CH}_{3} \mathrm{NH}_{2}$ & -95.830100 & $-23.01^{\mathrm{a}}$ \\
$\mathrm{CH}_{3} \mathrm{NHCH}_{3}$ & -135.117684 & $-18.8^{\mathrm{a}}$ \\
Title compound & -2638.672921 & 1643.265 \\
$\mathrm{HNIW}$ & -1790.961442 & $691.30^{\mathrm{c}}$ \\
\hline
\end{tabular}

${ }^{\mathrm{a}}$ From ref. ${ }^{36}$; ${ }^{\mathrm{f}}$ from ref. ${ }^{37}$; ${ }^{\mathrm{c}}$ from ref. ${ }^{38}$ used to roughly predict the impact sensitivities of the explosives. ${ }^{42}$

$$
\mathrm{OB}_{100}=\frac{n_{O}-\left(0.5 * n_{H}+2 n_{C}\right)}{M} \times 16,
$$

where $n_{O}, n_{H}$ and $n_{C}$ represent the numbers of $\mathrm{O}, \mathrm{H}$ and $\mathrm{C}$ atoms, respectively; $M$ is the molecular weight.

Table 2 lists the calculated condensed HOF $\Delta H_{f, \text { solid }}$, $V, \rho, D, P, Q$ and the oxygen balances $\left(\mathrm{OB}_{100}\right)$ of the title compound. The experimental data ${ }^{38,43}$ of hexahydro-1,3,5-trinitro-1,3,5-triazine (RDX), 1,3,5,7tetranitro-1,3,5,7-tetraazacyclooctane (HMX) and HNIW are also listed in table 2.

It is noted that value of $D$ and $P$ for the title compound are $12.22 \mathrm{~km} / \mathrm{s}$ and $67.70 \mathrm{GPa}$, respectively. And the values of $D, P$ of the title compound are all larger than those of RDX, HMX and HNIW. That is to say that the values of $D, P$ of the title compound satisfy the quantitative standard of high energetic density compound (HEDC) $\left(\rho \approx 1.9 \mathrm{~g} / \mathrm{cm}^{3}, D \approx 9.0 \mathrm{~km} / \mathrm{s}\right.$, $P=40 \mathrm{GPa}) .{ }^{44}$

\subsection{Thermal stability}

The main concern of the authors for the energetic materials is whether they are kinetically stable enough to be of practical interest. A good candidate HEDM should have a high stability. Thus, studies on the bond dissociation or pyrolysis mechanism are important and essential for understanding the decomposition process of the energetic materials because they are directly relevant to the sensitivity and stability of the energetic compounds. At present, there is a consensus that nitro groups often represent the primary cause of initiation reactivity of organic polynitro compounds. ${ }^{45,46}$ For the studied molecule, the collapse of the cage may happen since the cage compounds are always subject to a certain amount of strain energy.

In this paper, two possible initial steps, i.e., the breaking of $\mathrm{N}-\mathrm{NO}_{2}$ bond in the side chain and $\mathrm{C}-\mathrm{N}$ bond in the skeleton, are considered. Bond order is a measure of the overall bond strength between two atoms. A high value of the bond order indicates a covalent bond, whereas a low value shows an ionic nature. In order to find the weakest bond strength, natural bond orbital analysis (NBO) has been performed. Table 3 lists some Wiberg bond orders of the title compound. It is noted that $\mathrm{C}_{4}-\mathrm{N}_{6}$ in the cage skeleton and $\mathrm{N}_{9}-\mathrm{NO}_{2}$ in the side chain have the smaller wiberg bond index (WBI) among the same kind of bonds. The corresponding bond dissociation energies (BDEs) are also calculated and listed in table 3. It is noted that the BDE of $\mathrm{N}_{9}-\mathrm{NO}_{2}$ 
Table 2. Predicted density and detonation properties of the title compound. ${ }^{\text {a }}$

\begin{tabular}{lcccccc}
\hline Compound & $\Delta_{f, \text { solid }}$ & $\mathrm{OB}_{100}$ & $V$ & $\rho$ & $D$ & $P$ \\
\hline Title compound & 1311.16 & -0.73 & 371.451 & 1.87 & 12.22 & 67.70 \\
RDX $^{\mathrm{b}}$ & - & -0.22 & - & $1.74(1.81)$ & $8.98(8.75)$ & $35.13(34.7)$ \\
HMX $^{\mathrm{b}}$ & - & -0.22 & - & $1.89(1.90)$ & $9.35(9.10)$ & $38.24(39.0)$ \\
HNIW $^{\mathrm{c}}$ & - & -0.11 & 223.767 & $1.957(1.970)$ & 9.732 & 44.64 \\
\hline
\end{tabular}

${ }^{\mathrm{a}}$ Units: $\Delta H_{f, \text { solid }} /\left(\mathrm{kJ} \mathrm{mol}^{-1}\right) V /\left(\mathrm{cm}^{3} \mathrm{~mol}^{-1}\right), \rho /\left(\mathrm{g} \mathrm{cm}^{-3}\right), D /\left(\mathrm{km} \mathrm{s}^{-1}\right), P /(\mathrm{GPa})$

${ }^{\mathrm{b}}$ Data in parentheses are the experimental values taken from ref. ${ }^{43}$

${ }^{\mathrm{c}}$ Data from ref. ${ }^{38}$

is $109.60 \mathrm{~kJ} / \mathrm{mol}$, which is weaker than that of $\mathrm{C}_{4}-$ $\mathrm{N}_{6}$ bond $(205.47 \mathrm{~kJ} / \mathrm{mol})$. This indicates that $\mathrm{N}_{9}-\mathrm{NO}_{2}$ break more easily and may be the trigger bond. Obviously, the title compound is a stable compound according to the stability request of HEDC $(\mathrm{BDE} \approx 80 \sim$ $120 \mathrm{~kJ} / \mathrm{mol}$ ).

In addition, there exists a good linear relationship between the WBIs of $\mathrm{N}-\mathrm{NO}_{2}$ bonds and the charges $-\mathrm{Q}_{\mathrm{NO} 2}$ on the nitro groups (figure 3 ). The linear correlation coefficient is 0.96 . This shows that the charges on the nitro groups can be used to identify the strength of $\mathrm{N}-\mathrm{NO}_{2}$ bonds or the stability of the nitro compounds.

\subsection{Molecular packing prediction and density}

In this paper, COMPASS force field ${ }^{47}$ is used to predict the crystal structure of the title compound because it can produce the gas and condensed-phase properties reliably for a broad range of systems. ${ }^{48}$ Using COMPASS force field, the arrangements in all reasonable space groups are packed to search for the low-lying minima in the lattice energy surface. The structure optimized by B3LYP/6-31G** method is considered as

Table 3. Wiberg bond order, charges on nitro groups(e) and BDEs $(\mathrm{kJ} / \mathrm{mol})$ of the title compound.

\begin{tabular}{lccccc}
\hline Bond & WBI & Bond & WBI & $-\mathrm{Q}_{\mathrm{NO} 2}$ & BDE \\
\hline $\mathrm{C}_{1}-\mathrm{N}_{1}$ & 0.9647 & $\mathrm{~N}_{1}-\mathrm{N}_{2}$ & 0.9594 & - & - \\
$\mathrm{C}_{2}-\mathrm{N}_{1}$ & 0.9783 & $\mathrm{~N}_{3}-\mathrm{N}_{4}$ & 0.9681 & - & - \\
$\mathrm{C}_{1}-\mathrm{N}_{3}$ & 0.9674 & $\mathrm{~N}_{5}-\mathrm{N}_{6}$ & 0.9669 & - & - \\
$\mathrm{C}_{2}-\mathrm{N}_{4}$ & 0.9687 & $\mathrm{~N}_{7}-\mathrm{NO}_{2}$ & 0.9638 & 0.07626 & - \\
$\mathrm{C}_{3}-\mathrm{N}_{2}$ & 0.9560 & $\mathrm{~N}_{8}-\mathrm{NO}_{2}$ & 1.0136 & 0.14031 & - \\
$\mathrm{C}_{4}-\mathrm{N}_{2}$ & 0.9916 & $\mathrm{~N}_{9}-\mathrm{NO}_{2}$ & 0.9553 & 0.0946 & 109.60 \\
$\mathrm{C}_{3}-\mathrm{N}_{5}$ & 0.9392 & $\mathrm{~N}_{10}-\mathrm{NO}_{2}$ & 0.9913 & 0.10306 & - \\
$\mathrm{N}_{4}-\mathrm{C}_{6}$ & 0.9684 & $\mathrm{~N}_{11}-\mathrm{NO}_{2}$ & 1.0302 & 0.15841 & - \\
$\mathrm{C}_{5}-\mathrm{N}_{5}$ & 0.9234 & $\mathrm{~N}_{12}-\mathrm{NO}_{2}$ & 1.0443 & 0.16417 & - \\
$\mathrm{N}_{6}-\mathrm{C}_{6}$ & 0.9531 & & & & - \\
$\mathrm{N}_{3}-\mathrm{C}_{5}$ & 0.9643 & & & & - \\
$\mathrm{C}_{4}-\mathrm{N}_{6}$ & 0.9205 & & & & 205.47 \\
\hline
\end{tabular}

input structure for polymorph search. Table 4 lists the lattice parameters in all reasonable space groups.

It is noted from table 4 that the energies range from -429.5 to $-437.1 \mathrm{~kJ} \mathrm{~mol}^{-1}$ cell $^{-1}$ and the structure with $\mathrm{P} 2{ }_{1} / \mathrm{C}$ symmetry has the lowest energy, so the title compound tends to exist in the $\mathrm{P} 2_{1} / \mathrm{C}$ group. The corresponding lattice parameters are $\mathrm{Z}=4, \mathrm{a}=12.3421 \AA$, $\mathrm{b}=24.6849 \AA, \mathrm{c}=20.4912 \AA, \rho=1.896 \mathrm{~g} \mathrm{~cm}^{-3}$. Figure 4 gives the molecular packing of the title compound in $\mathrm{P} 2{ }_{1} / \mathrm{C}$ space group.

\subsection{Thermodynamic properties}

Based on the scaled vibrational frequencies, the thermodynamic functions including standard molar heat capacity $C_{p, m}^{0}$, entropy $S_{p, m}^{0}$ and enthalpy $H_{p, m}^{0}$, are obtained based on statistical thermodynamic principle. The temperature-dependent relations for the thermodynamic functions are expressed in figure 5. It is noted that all thermodynamic properties increase with the increase of temperature because of the larger contribution of vibrational movement at the higher temperature.

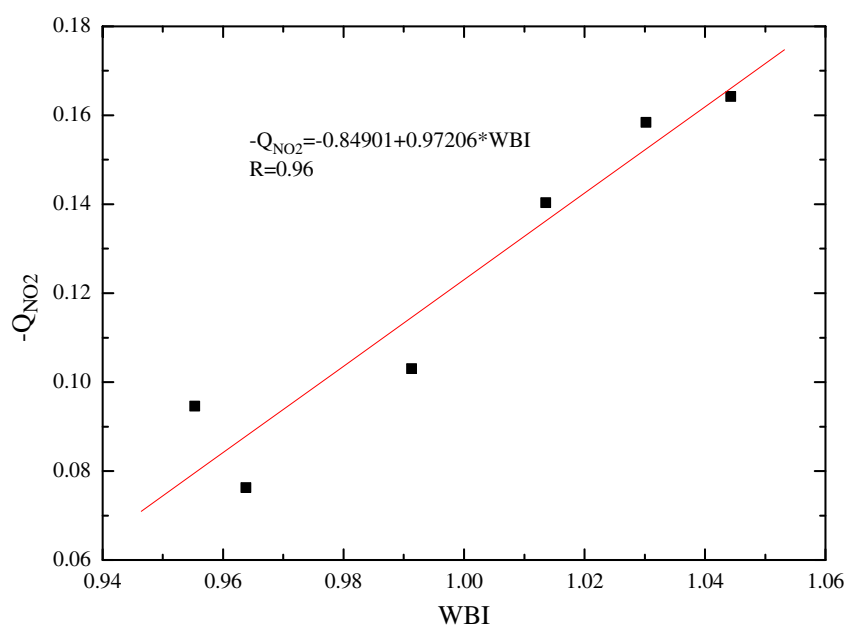

Figure 3. The relationship between $-\mathrm{Q}_{\mathrm{NO} 2}$ and $\mathrm{WBI}$ for the title compound. 
Table 4. Unit cell parameters of the possible molecular packing of the title compound.

\begin{tabular}{lccccccc}
\hline Space groups & $\mathrm{C} 2 / \mathrm{c}$ & $\mathrm{P} 1$ & $\mathrm{P} 2_{1} 2_{1} 2_{1}$ & $\mathrm{P} 2_{1}$ & $\mathrm{P} 2_{1} / \mathrm{C}$ & $\mathrm{Pna} 2_{1}$ & $\mathrm{Pbca}$ \\
\hline $\mathrm{Z}$ & 8 & 2 & 4 & 2 & 4 & 4 & 8 \\
$\mathrm{E}\left(\mathrm{kJ} \mathrm{mol}^{-1} \mathrm{cell}^{-1}\right)$ & -414.2 & -431.5 & -434.7 & -435.3 & -437.1 & -434.1 & -429.5 \\
$\rho\left(\mathrm{g} \mathrm{cm}^{-3}\right)$ & 1.896 & 1.925 & 1.937 & 1.947 & 1.896 & 1.95 & 1.912 \\
$\mathrm{a}(\AA)$ & 47.8283 & 37.4348 & 30.4101 & 13.9580 & 12.3421 & 19.6776 & 16.0664 \\
$\mathrm{~b}(\AA)$ & 30.4715 & 11.4512 & 17.8877 & 15.2985 & 24.6849 & 16.1024 & 21.0515 \\
$\mathrm{c}(\AA)$ & 15.4340 & 9.21775 & 12.1826 & 12.0480 & 20.4912 & 16.1091 & 41.7392 \\
$\alpha$ & 90 & 77.6063 & 90 & 90 & 90 & 90 & 90 \\
$\beta$ & 100 & 63.7499 & 90 & 108.332 & 99.056 & 90 & 90 \\
$\gamma$ & 90 & 78.9366 & 90 & 90 & 90 & 90 & 90 \\
\hline
\end{tabular}

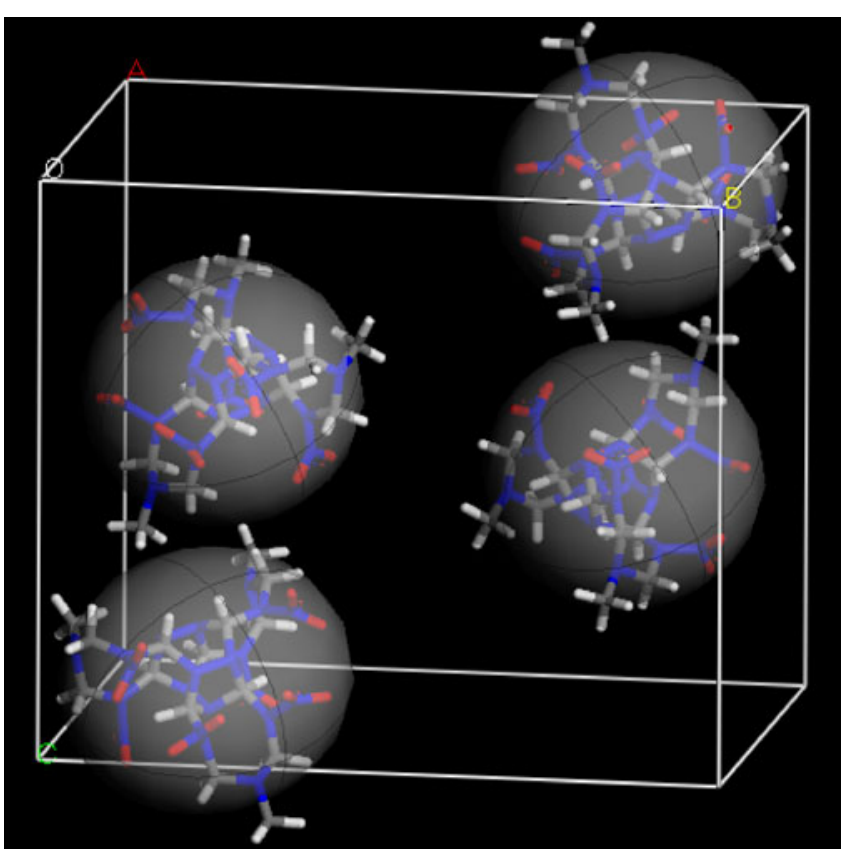

Figure 4. Molecular packing of the title compound in $\mathrm{P} 2{ }_{1} / \mathrm{C}$ space group.

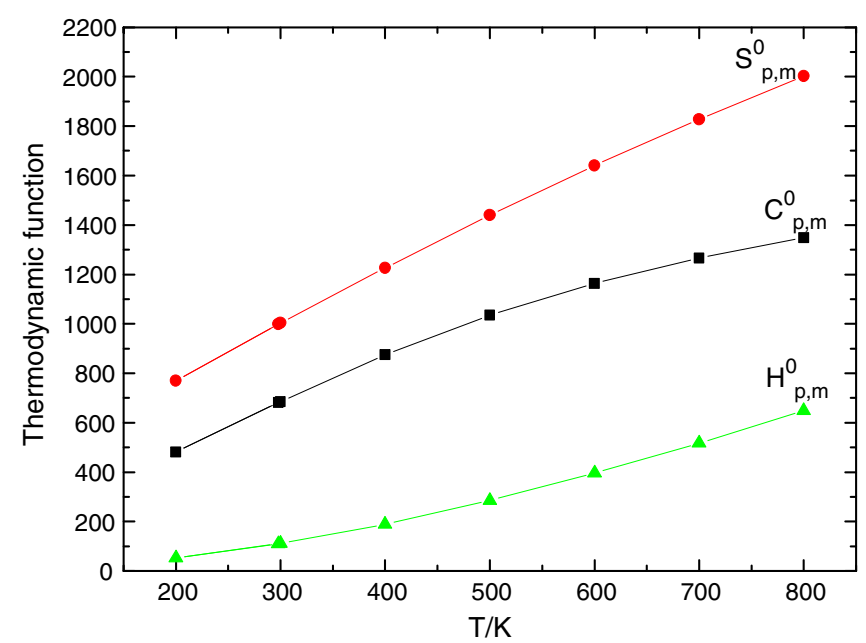

Figure 5. The relationships between the thermodynamic functions and temperature (T) for the title compound.

\section{Conclusion}

In this paper, theoretical investigations have been performed on a new designed poly nitro cage compound HNIW derivative by using DFT. IR spectrum, detonation properties, $\mathrm{HOF}$ and the weakest bond were predicted. The results show that the title compound possesses very high HOF, detonation velocity and pressure. There exists an essentially linear relationship between the WBIs of $\mathrm{N}-\mathrm{NO}_{2}$ bonds and the charges $-\mathrm{Q}_{\mathrm{NO} 2}$ on the nitro groups. The $\mathrm{N}_{9}-\mathrm{NO}_{2}$ bond is predicted to be the trigger bond during pyrolysis based on the results of bond order and bond dissociation energy. The most possible packing structure belongs to $\mathrm{P} 2 / \mathrm{C}$ space group. All the calculation results indicate that the title compound possesses very high HOF, detonation velocity and pressure and is a potential candidate of HEDM.

\section{Supplementary information}

The electronic supporting information can be seen in www.ias.ac.in/chemsci.

\section{Acknowledgements}

Authors thank the Postdoctoral Science Foundation of China (No. 2013M531361), the grant from Development Program in Science and Technology of Henan Province (No. 122102210427) and Jiangsu Planned Projects for Postdoctoral Research Funds (No. 1201015B) for their support to carry out this work.

\section{References}

1. Denffer M V, Klapotke T M, Kramer G, Spei G, Welch J and Heeb G 2005 Prop. Explos. Pyrotech. 30191

2. Klapotke T M, Karaghiosoff K, Mayer P, Penger A and Welch J M 2006 Prop. Explos. Pyrotech. 31188

3. Churakov A M, Smirnov O Y, Ioffe S L, Strelenko Y A and Tartakovsky V A 2002 Eur. J. Org. Chem. 142342

4. Badgujar D M, Talawar M B, Asthana S N and Mahulikar P P 2008 J. Hazard Mater. 151289 
5. Talawar M B, Sivabalan R and Senthilkumar N J 2004 J. Hazard Mater. 11311

6. Nielsen A T, Nissan R A, Vanderah D J, Coon C L, Gilardi R D, George C F and Anderson J F 1990 J. Org. Chem. 551459

7. Eaton P E, Zhang M, Gilardi R, Gelber N, Iyer S and Surapaneni R 2002 Propell. Explos. Pyrot. 271

8. Eaton P E, Gilardi R L and Zhang M X 2000 Propell. Explos. Pyrot. 121143

9. Schulman J M and Disch R L 1984 J. Am. Chem. Soc. 1061202

10. Xu X J, Xiao H M, Gong X D, Ju X H and Chen Z X 2005 J. Phys. Chem. A 10911268

11. Stetter H, Mayer J, Schwarz M and Wolff K 1960 Chem. Ber. 93226

12. Sun C H, Zhao X Q, Li Y C and Pang S P 2010 Chin. Chem. Lett. 21572

13. Zhang J Y, Du H C, Wang F, Gong X D and Huang Y S 2011 J. Phys. Chem. A 1156617

14. Li X H, Zhang R Z and Zhang X Z 2010 J. Hazard Mater. 183622

15. Li X H, Cheng Q D and Zhang X Z 2010 J. Energ. Mater. 28251

16. Xu X J, Xiao H M, Ju X H, Gong X D and Zhu W H 2006 J. Phys. Chem. A 1105929

17. Frisch M J, Trucks G W, Schlegel H B, Scuseria G E, Robb M A, Cheeseman J R, Zakrzewski V G, Montgomery J A, Stratmann R E, Burant J C, Dapprich S, Millam J M, Daniels A D, Kudin K N, Strain M C, Farkas O, Tomasi J, Barone V, Cossi M, Cammi R, Mennucci B, Pomelli C, Adamo C, Clifford S, Ochterski J, Petersson G A, Ayala P Y, Cui Q, Morokuma K, Malick D K, Rabuck A D, Raghavachari K, Foresman J B, Cioslowski J, Ortiz J V, Baboul A G, Stefanov B B, Liu G, Liashenko A, Piskorz P, Komaromi I, Gomperts R, Martin R L, Fox D J, Keith T, Al-Laham M A, Peng C Y, Nanayakkara A, Gonzalez C, Challacombe M, Gill P M W, Johnson B, Chen W, Wong M W, Andres J L, Gonzalez C, Head Gordon M, Replogle E S and Pople J A 2003 GAUSSIAN 03, Revision B.02 (Pittsburgh PA: Gaussian Inc.)

18. Scott P and Radom L 1996 J. Phys. Chem. 10016502

19. Kamlet M J and Jacobs S J 1968 J. Chem. Phys. 4823

20. Zhang X H and Yun Z H 1989 Explosive chemistry (Beijing: National Defense Industry Press)

21. Qiu L, Xiao H M, Ju X H and Gong X D 2005 Int. J. Quantum Chem. 10548

22. Xiao J J, Zhang J, Yang D and Xiao H M 2002 Acta Chim. Sinica 602110

23. Zhang J and Xiao H M 2002 J. Chem. Phys. 11610674
24. Ju X H, Xiao J J, Li Y and Xiao H M 2003 Chinese J. Struct. Chem. 22223

25. Liu M H, Chen C and Hong Y S 2004 J. Mol. Struct. (Theochem) $\mathbf{7 1 0} 207$

26. Qiu L, Xiao H M, Gong X D, Ju X H and Zhu W 2007 J. Hazard. Mater. 141280

27. Materials Studio Blends module, Version 4.4; software for miscibility estimation: Theory in Blends, 2008 (San Diego, CA: Accelrys Software Inc)

28. Chernikova N Y, Belsky V K and Zorkii P M 1990 J. Struct. Chem. 31661

29. Mighell A D, Himes V L and Rodgers J R 1983 Acta Crystallogr. 39737

30. Wilson A J C 1988 Acta Crystallogr. A 44715

31. Srinivasan R 1992 Acta Crystallogr. A 48917

32. Baur W H and Kassner D 1992 Acta Crystallogr. B 48 356

33. Benson S W 1976 Thermochemical kinetics (New York: Wiley Interscience)

34. Yao X Q, Hou X J, Wu G S, Xu Y Y, Xiang H W, Jiao H and Li Y W 2002 J. Phys. Chem. A 1067184

35. Hehre W J, Radom L and Schleyer P V R 1986 Ab initio molecular orbital theory (New York: Wiley)

36. Lide D R (ed.) 2004 Handbook of chemistry and physics, 84th ed. (Boca Raton, FL: CRC Press LLC)

37. NIST Standard Reference Data Base Number 69, (http:// webbook.nist.gov/chemistry)

38. Ghule V D, Jadhav P M, Patil R S, Radhakrishnan S and Soman T 2010 J. Phys. Chem. A. 114498

39. Kamlet M J and Jacobs S J 1968 J. Chem. Phys. 4823

40. Zhang X H and Yun Z H 1989 Explosive chemistry (Beijing, People's Republic of China: National Defence Industry Press)

41. Byrd C E F and Rice B M 2006 J. Phys. Chem. A. 110 1005

42. Kamlet M J and Adolph H G 1979 Propellants, Explos., Pyrotech. 430

43. Sasada Y 1984 Molecular and crystal structures in chemistry handbook, 3rd ed. (Tokyo: The Chemical Society of Japan, Maruzen)

44. Xiao H M, Xu X J and Qiu L 2008 Theoretical design of high energy density materials (Beijing: Science Press)

45. Pospíšil M, Vávra P, Concha M C, Murray J S and Politzer P 2011 J. Mol. Model. 172569

46. Murray J S, Concha M C and Politzer P 2009 Mol. Phys. 10789

47. Sun H 1998 J. Phys. Chem. B. 1027338

48. Xu X J, Zhu W H and Xiao H M 2007 J. Phys. Chem. B. 1112090 